\title{
Compartint el mateix cendrer: Martí de Riquer i Josep Romeu Isabel de Riquer
}

\begin{abstract}
A l'Arxiu Riquer es conserven dotze cartes de Josep Romeu Figueras (Òdena, l'Anoia, 1917Barcelona, 2004) adreçades a Martí de Riquer (Barcelona, 1914-2013), que van des del 19-VI50 fins al 16 d'abril de 1986.' L'arxiu personal i la biblioteca particular del Dr. Romeu es troben al Fons Josep Romeu i Figueras de la Biblioteca Central d'Igualada per expressa voluntat seva, manifestada al seu testament. ${ }^{2}$ Els llibres de Romeu, tant els que va escriure ell mateix com els de la seva biblioteca, estan tots catalogats i, per tant, són consultables al catàleg. També hi ha documents originals com les cartes que va rebre, fullets, separates, revistes i les tesis doctorals que va dirigir. Les cartes de Martí de Riquer conservades en aquest fons no són gaires: una del 7 de març de 1969 (en resposta a una de Romeu del 5-II-69); una postal del barri de Les Tres Torres de Barcelona en què s'indica el nou domicili dels Riquer, al dors de la qual es pot llegir escrit a mà «Feliç 1975 i us oferim la nostra casa. Riquer»; una carta del 24 d'octubre de 1975, una altra del 8 de març de $1987 \mathrm{i}$ les còpies de dues cartes escrites per Romeu a Riquer el 19-v-69, l'original d'una de les quals es troba a l'Arxiu Riquer i l'altra, que va adreçada a Riquer com a President de la Reial Acadèmia de Bones Lletres, es deu trobar a l'arxiu d'aquesta institució.

Encara que per als lectors de la revista Mot so razo el Dr. Romeu i la seva obra, tant la in-
\end{abstract}

\footnotetext{
1. Transcric les dates tal com apareixen a les cartes.

2. El meu agraïment a la senyora Dolors Palomas Castellví, tècnica auxiliar de la Biblioteca Central d'lgualada, per fer-me arribar escanejades les cartes de $M$. de Riquer adreçades al Dr. Josep Romeu i per respondre amb amabilitat les meves preguntes i resoldre els meus dubtes amb promptitud.
}

vestigadora com la personal (poemes, dietaris, memòries, etc.), són prou coneguts, en faré uns breus apunts biogràfics (Diccionari biogràfic 2012: 369-71.3.3 Poeta, crític literari, estudiós de la literatura i del teatre medievals i dels poetes catalans contemporanis, Josep Romeu i Figueras estudià a la Universitat de Barcelona i als Estudis Universitaris Catalans, on es va doctorar en lletres l'any 1948. Del 1971 al 1984 fou professor d'investigació al Consell Superior d'Investigacions Científiques, adscrit a l'Institut Espanyol de Musicologia, i entre 1969 i 1984 fou professor de literatura catalana a la Universitat Autònoma de Barcelona. El 1972 ingressà a l'Acadèmia de Bones Lletres de Barcelona i fou membre d'honor de l'Associació d'Escriptors en Llengua Catalana. Li fou atorgada la Creu de Sant Jordi l'any 1993 i el 2004, el Premi Crítica Serra d'Or de biografies i memòries per Quadern de memòries. No només va ser medievalista, sinó que també va fer crítica literària d'autors catalans com Joan Maragall, Josep Vicenç Foix, Carles Riba, Joan Brossa i Bartomeu Rosselló-Pòrcel.

Tanmateix, per parlar de la seva relació amb Martí de Riquer hem de fixar-nos en primer lloc en la carta que Romeu li va escriure el 19-VI-1950:

Bon amic Riquer: M'he enterat que avui et feien un homenatge amb motiu del teu èxit en les oposicions. No he estat convidat i no he tingut, per tant, ocasió d'assistir-hi. Pensa, però, que no sols m'hi adhereixo ben sincerament, sinó que a més considero que te'l mereixes de debò. Has portat unes oposicions i uns exercicis amb un nivell cultural elevadíssim, fins a tal punt que no sé si admirar més el talent de

3. Per a la biografia de Riquer, vegeu Gatell \& Soler (2008) i el Diccionari biogràfic (2012: 361-62). 
l'opositor triomfant o la seva voluntat tenaç. A més, estic content perquè tot va desenrotllar-se sota la més absoluta correcció i en un ambient de completa cavallerositat; és, aquesta, l'única forma de lluitar que entenc i admeto.

Voldria que la nostra rivalitat d'uns dies hagués servit de motiu per a una més estreta amistat. Per la meva banda, ja saps quines són les meves disposicions en aquest aspecte.

Et felicito novament i que per molts anys puguis disfrutar del teu triomf.

I, a sota, la seva rúbrica, que és un traç gairebé vertical.

Tres dies més tard (22-VI-1950), Romeu envia a Riquer una còpia de la carta, manuscrita i en paper del Consejo Superior de Investigaciones Científicas. Instituto Español de Musicología, que havia escrit al degà de la Facultat de Filosofia i Lletres, José Ma Castro y Calvo, dient-li:

Ante el merecido homenaje que la Facultad ofrece al Dr. Martín de Riquer con motivo de haber obtenido la Cátedra de «Historia de las literaturas románicas» para la Universidad de Barcelona, le agradeceré muy encarecidamente se sirva aceptar mi adhesión más sincera. Tal vez nadie como yo pueda dar un testimonio más directo y vivo del alto tono intelectual y de la seguridad con que el Dr. Riquer llevó a cabo las oposiciones que le han valido la cátedra, ni de su justificado triunfo como coronación de sus esfuerzos perseverantes y de su larga labor investigadora y universitaria. Creo un deber dar constancia de ello y homenajear, de este modo, a mi antiguo compañero de oposición.

Le saluda muy atentamente s.s. q.e.s.m.,

[la rúbrica]

F. José Romeu Figueras ${ }^{4}$

Aquestes dues cartes fan evident el gran afecte i la relació tan cordial i respectuosa que hi va haver entre tots dos collegues durant els llargs dies de la dura oposició a la càtedra d'«Historia de las literaturas románicas» de la Universitat de Barcelona, una càtedra que es creava per primera vegada a Espanya. A Madrid, del 29 de maig i fins al 16 de juny de 1950, els dos candidats van realitzar sis exercicis de temes teòrics i pràctics escollits a l'atzar, davant d'un tribunal presidit per

4. Les dues cartes són a l'Arxiu Riquer. Carpeta «Romeu i Figueras». mossèn Llorenç Riber, de la Real Academia Española, i que tenia per vocals els doctors Marià Bassols, catedràtic de Llatí de la Universitat de Barcelona, Dámaso Alonso, Joaquin de Entrambasaguas, i Rafael Balbín, que exercí de secretari; els tres darrers eren catedràtics de la Universitat de Madrid: el primer, de Filologia Romànica; el segon, de Literatura Espanyola, i el tercer, de Llengua Española (Gatell \& Soler 2008: 266-79).

Els avatars previs a aquestes oposicions, els recorda el Dr. Antoni Badia i Margarit, que l'any 1948 havia obtingut una càtedra de Lingüística a la mateixa facultat (Badia i Margarit 1989: 626 i Gatell \& Soler 2008: 268-69):

Cap a la fi dels anys quaranta del segle passat, quan diversos companys ens mesuràvem les forces per les oposicions de càtedra, fou convocada la d'Història de les Literatures Romàniques de la Universitat de Barcelona (1950). Calia refer la malparada Universitat barcelonina i el Ministeri hi estava aportant remei (com és sabut, el 1948 jo mateix acabava de tapar-hi un forat, amb una càtedra de lingüística). La reacció de la gent de casa nostra (universitaris i no universitaris) fou d'absoluta unanimitat: Martí de Riquer era el candidat idoni. Del mateix parer era Josep Romeu. Tanmateix, cavillós com era, passà uns dies donant-li voltes i, a la fi, vingué a demanar-me opinió i consell: i si es presentava, també ell, en aquestes oposicions? Ara no puc estendre-m'hi i haig d'anar al gra. La meva resposta feia més o menys així: 1) ningú no es penedeix d'haver signat una sollicitud d'opositor (a l'inrevés, podria passar que un dia li sabés greu de no haver fet); 2) nosaltres (és a dir, ell i jo) comencem i forçosament tenim poca obra feta, però en Riquer té al darrera un bagatge extraordinari i una enorme capacitat de treball, i no t'hi podries fer gaires illusions, i 3) fer unes oposicions és ficar-se en una mena de taller on no s'hi perd res, on et dónes a conèixer a la gent de l'ofici, on t'autoimposes una preparació que, si no, no trobaries mai l'hora de procurar-te $i$ on s'hi pot aprendre molt. Així ho deixàrem. A mi, però, no em costà d'endevinar quina seria la seva decisió definitiva: tenaç com era, Josep Romeu se n'anà a Madrid, féu les oposicions $i$, tot i preveure'n el resultat del primer exercici ençà, s'hi mantingué fins a la fi. Riquer obtingué la càtedra, amb una indiscutible aurèola de guanyador i en Romeu en reconegué el veredicte i felicità de cor el seu con- 
trincant (la cosa més important era que amics eren abans, i amics continuaren essent després). ${ }^{5}$

Martí de Riquer rememora aquelles oposicions: «A les oposicions [les quals havien signat dues persones més], només s'hi va presentar en Josep Romeu Figueras, un poeta i erudit molt amic meu, i entre nosaltres no hi va haver el més petit frec» (Gatell \& Soler 2008: 273). L'acta del tribunal del 16 de juny de 1950 reflecteix que Martí de Riquer va ser designat per unanimitat per ocupar la càtedra i només tres dies més tard rebia la sincera i cordial felicitació de Josep Romeu, que hem copiat més amunt.

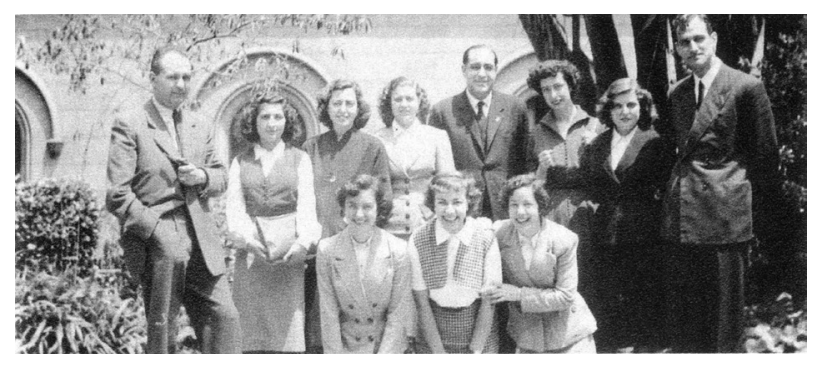

Martí de Riquer a la Universitat de Barcelona (1954), amb Antoni M. Badia i Margarit a la dreta de la imatge.

Una carta de Romeu del 31-1I-65 és la resposta al condol que Riquer li va escriure per la mort de la seva esposa Teresa Costa i Llucià. La resposta de Romeu (no es conserva la carta de Riquer al Fons Romeu) reflecteix el seu estat de tristesa profunda i una confiança íntima en el seu amic com la que demostren aquestes poques línies que en reproduïm:

\section{Benvolgut amic,}

Vaig rebre, ahir, la teva carta de condol per la mort de la meva esposa. No saps com l'agraeixo, més que més per la invocació que hi fas de la nostra vella amistat, realment vàlida en hores com aquestes, tan amargues i sobretot lacerants en la meva monòtona, interminable continuïtat de cada instant. [...] El meu fill i jo, tanmateix, amb resignació i fent front als dies, procurem sobreposar-nos i refer-nos del desastre, el

5. Dos exemplars de la «Memòria» de les oposicions de Romeu titulada Historia de las literaturas románicas y comentario estilístico de textos clásicos y modernos románicos: memoria sobre Problemática y Metodología de la asignatura Historia de las literaturas románicas, 1950, es troben dipositats al Fons de la Biblioteca Central d'lgualada. de la pèrdua i també el que suposa el trontoll convulsiu de tantes coses que havíem cregut, enganyosament, molt sòlides. [...]

Salutacions respectuoses a la teva muller.

Una abraçada del teu bon amic.

El gener de 1964, Martí de Riquer va prendre possessió de la presidència de la Reial Acadèmia de Bones Lletres, -n'havia estat nomenat membre el 1941 i va fer el discurs d'ingrés el 26 de març de 1944 (Gatell \& Soler 2008: 443-69). ${ }^{6}$ Des del moment que Riquer fou elegit president, una de les seves grans preocupacions fou aconseguir que el palau Requesens fos exclusivament seu de l'Acadèmia i aconseguir subvencions de tot arreu, públiques i privades, per restaurar l'edifici i dotar-lo d'unes mínimes condicions d'habitabilitat (reparar la teulada, els mobles, la calefacció, els serveis, l'habilitació de despatxos, la compra de llibres, el personal, el manteniment de l'immoble...). El Ministerio de Educación y Ciencia, en un decret de juny de 1975, va declarar el Palau Requesens «Monumento Histórico-Artístico de Carácter Nacional»»? El vincle de l'Acadèmia amb la Universitat es va afermar en aquella època amb l'ingrés com a acadèmics d'un gran nombre de professors de les universitats catalanes, amb la qual cosa es va produir una important renovació generacional i una major pluralitat de disciplines entre els acadèmics, que encara avui caracteritza l'Acadèmia. Les especialitats dels acadèmics eren i són totes aquelles que comprèn la vella expressió francesa de Belles Lettres (que el nom de l'Acadèmia reflecteix), que es refereix no només a la Literatura i a la Llengua, sinó també a la Història, l'Arqueologia, la Geografia, les Belles Arts des del seu vessant històric i tot allò que abastava l'antiga carrera de Filosofia i Lletres i que avui hom coneix per Humanitats. El nombre total d'acadèmics és de trenta-vuit.

\footnotetext{
6. Riquer va ser president de la Reial Acadèmia de Bones Lletres de Barcelona fins al 1996.

7. Carta de Riquer a Romeu del 24 d'octubre del 1975, en la qual l'informa que a causa de «les obres de restauració i endreç del darrer pis del nostre local corporatiu i d'installació de l'ascensor [...] hom preveu que el nostre local corporatiu no oferirà condicions per a celebrar-hi les sessions ordinàries fins mitjan de desembre».
} 
Les principals activitats de l'Acadèmia han estat sempre les seves sessions acadèmiques (abans cada quinze dies i ara un dijous cada mes) en les quals un acadèmic exposa un tema que està treballant perquè els altres acadèmics facin les seves observacions. Una de les preocupacions de Riquer havia estat sempre que les conferències, debats i altres aportacions intellectuals quedessin enregistrades sempre per escrit. En aquest sentit, només d'entrar a l'Acadèmia, va ocupar-se de la publicació del «Boletín» (ara «Butlletí»), el primer després de la Guerra Civil.

El vint de febrer de 1969 els acadèmics Pere Bohigas, Guillem Díaz-Plaja i Josep Vives Gatell van proposar la candidatura de Josep Romeu i Figueras. Unes setmanes més tard Romeu escriu a Riquer (5-1I-69) manifestant-li la seva satisfacció per formar part de la prestigiosa institució. A la primera de les dues cartes relacionades amb aquest tema, li diu que «ja ho he fet personalment i per telèfon, però penso que és cortesia i de justícia que en doni constància per escrit. Gràcies, doncs, una vegada més!»;; i continua:

Sempre he cregut que la gent que treballen ho han de fer conectats amb directrius, amb institucions o amb altres moviments, més fluids i menys precisos, i que l'aportació personal s'estructura, a la curta o a la llarga, en una projecció més sòlida i vertebrada de caire social i cultural. [...] comprenc que m'ha mancat, i en manca encara, conectar-me més decididament amb el treball de collegues i d'investigadors. Ara em proporciones una bona oportunitat que procuraré no menysprear. Per això puc dir-te que em tens a la teva disposició per treball en comú, corporatiu, dins les meves possibilitats, que, al capdavall i com tothom, fet i fet, no sé quines són en realitat, cada dia menys. Segur que em faig vell! Una abraçada.

La resposta de Riquer del 7 de març de 1969 és la següent:

\section{Estimat Romeu.}

Moltes gràcies per les teves ratlles. Em va fer molt goig veure ahir les teves publicacions a la taula de l'Acadèmia. Em fa illusió que hi treballem plegats.

Una forta abraçada del teu bon amic. [Rúbrica a mà]
Dues setmanes més tard (19-v-69) Romeu li torna a escriure, aquest cop a màquina: ${ }^{8}$

\section{Estimat amic,}

T'envio, a casa, la meva acceptació del nomenament, amb la responsabilitat que comporta. No sé si ho hauria d'haver enviat a l'Acadèmia, com la carta que faré al Secretari. Tampoc estic massa segur d'haver endevinat el to corresponent. No entenc gens de protocol. Només sé dir que sóc sincer i només sé dir-ho a la meva manera. Si et sembla que ho haig de fer d'una altra manera, tornaré a redactar les dues cartes. Aquestes, però, han sortit així d'espontànies, i penso que hem de ser com som, si som com hem de ser. I perdona el joc retòric, involuntari. [...] Ahir no vaig poder assistir a la recepció de l'Ainaud.9 Tinc els pares internats, a lgualada, des de fa un any, i ahir al matí em van avisar que un d'ells estava indisposat. Hi vaig anar, doncs. Afortunadament, fou una falsa alarma. El temps de primavera és dolent pels afectats d'apoplexia, i ells dos n'estan.

Rep tot l'afecte del teu bon amic.

Del mateix dia, el Fons Romeu conserva la còpia que va fer d'una altra carta de caire més oficial, ja que va dirigida al

Excm. Sr.

Dr. Martí de Riquer

President de la Reial Acadèmia de Bones Lletres de Barcelona

Ciutat

Benvolgut amic,

amb data d'avui escric al senyor Josep Alsina, Secre-

8. Una còpia d'aquesta carta només es conserva al Fons Romeu de la Biblioteca Central d'Igualada.

9. Joan Ainaud de Lasarte (Barcelona 1919-1995), historiador. Va ser professor de la Universitat Autònoma de Barcelona (1968-78), on va esdevenir un dels fundadors del departament d'Història de l'Art. Home de coneixements enciclopèdics, fou especialista en art medieval —romànic i gòtic — i del Renaixement a Catalunya, però també va fer aportacions importants a l'art contemporani, especialment a la figura de Pablo Picasso. Joan Ainaud va ingressar a l'Acadèmia el 18v-1969 amb un discurs sobre les Pintures del segle XIII al carrer de Montcada de Barcelona, aleshores recentment descobertes al palau Aguilar (avui al Museu Nacional d'Art de Catalunya), dedicades a la conquesta de Mallorca per Jaume l i considerades la representació més important d'una crònica històrica en la pintura medieval catalana (Diccionari biogràfic 2012: 20-21). 


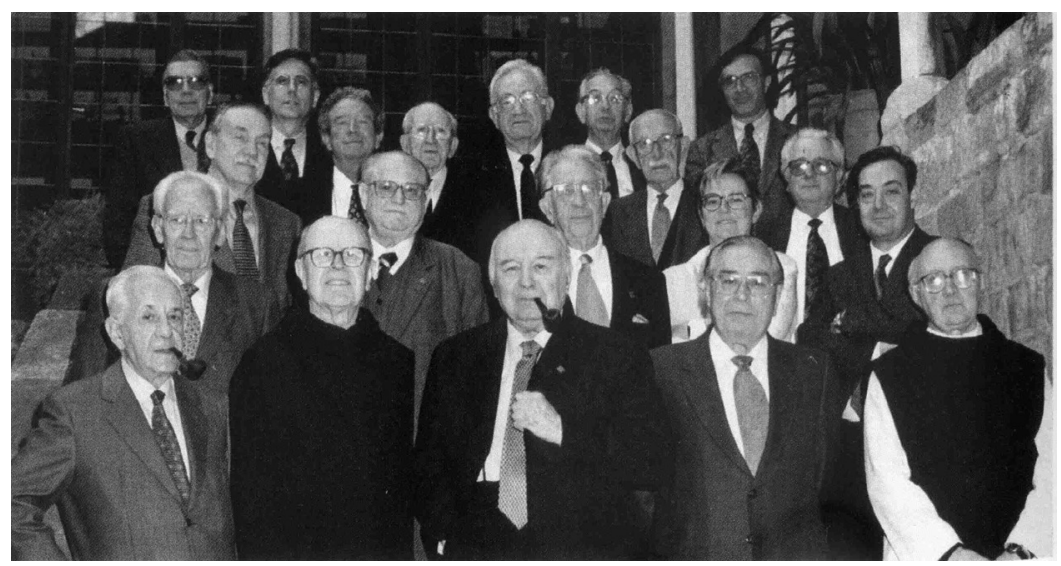

Josep Romeu i Martí de Riquer, a primera fila, amb els membres de l'Acadèmia el 1997.

tari d'aquesta Acadèmia, acusant rebut de la carta que m'adreçà el 9 dels corrents, comunicant-me haver estat elegit per unanimitat Acadèmic de Número per a ocupar la vacant produïda pel senyor Manuel de Montoliu, en virtut de la proposta presentada pels Acadèmics senyors Josep Vives, Pere Bohigas i Guillem Díaz-Plaja, en la sessió celebrada per la Reial Acadèmia de Bones Lletres, en data 8 d'aquest mes. I que he rebut, així mateix, els Estatuts i el Reglament de la Corporació, que he considerat detingudament i tota deferència.

Per un deure d'amistat $i$ per un imperatiu de justícia, tant com per consideracions d'ordre jeràrquic, en aquesta carta haig de fer constar amb prioritat i abans que no ho faci en l'altra, on ho reiteraré, que accepto molt honorat i amb goig l'alta distinció que m'ha estat conferida, i que sóc ben conscient de la responsabilitat a què em porten l'assentiment i el respecte, per la meva part, de les estructures bàsiques de la Institució i la promesa de complir les tasques científiques i corporatives a què aquesta m'obligui, d'acord amb les meves aptituds i bona voluntat. Pels mateixos motius, haig d'expressar aquí en particular, al president, allò mateix que en l'altra carta pregaré que es faci collectivament a tots els senyors Acadèmics, és a dir, la meva reconeixença, sincera i emocionada, per la generosa bondat de tots amb la promesa i l'esperança que evidenciarà en la pràctica l'autenticitat d'aquestes ratlles de gratitud $i$ afecte.

Gràcies, una vegada més!

Una abraçada

[sense signatura]

Josep Romeu Figueras va ingressar a l'Acadèmia el 20 de febrer de 1972 amb un discurs sobre Joan de Timoneda i la "Flor de enamorados" cançoner bilingüe. Un estudi i una aportació bibliogràfıca, contestat per Jordi Rubió i Balaguer (Barcelona 1887-1982). Se li va assignar la medalla XXVII, que havia estat de Manuel de Montoliu. L'estudi sobre Timoneda és una aportació fonamental al coneixement de la poesia de tipus tradicional difosa per la impremta al començament del segle XVI, amb un repàs detallat de les fonts de les peces líriques i narratives integrades en el recull anomenat Flor de enamorados i de les corresponents estructures mètriques i valor poètic.

Quatre dies desprès de la recepció (24-1I-72), Riquer rebia una carta manuscrita de Romeu:

\section{Benvolgut amic,}

et volia escriure l'endemà de la recepció. Però no vaig poder: massa cosa i massa emoció de la vigília m'haurien impedit de dir res amb una certa coherència. He esperat uns dies més, altrament, perquè m'havien de portar unes fotos. Avui les he rebudes i t'envio aquesta, en la qual estàs molt bé.

Gràcies per tot, per tantes coses, també. Sobretot, per l'actitud i l'afecte, que és el que preval i allò que més estimo. Tota la resta són circumstàncies i accidents, favorables o no, que al capdavall tenen un valor relatiu. Les teves paraules de clausura foren una comunicació entre tu ijo, que en comprenguérem el just abast. Per això vaig dir-te després que et devia una abraçada. Rep-la ara, i molt estreta i perllongada. La Núria va estar molt contenta de tot i per tot. Va augmentar — que ja és dir — la molta simpatia que sempre t'ha tingut. A la foto la tens al davant, i sembla que t'hi adrecis.'

Teu

[la rúbrica habitual]

10. Núria Font i Clavell, segona esposa del Dr. Josep Romeu. 
A partir d'aquell moment Romeu va participar d'una manera activa en les tasques acadèmiques esmerçant-hi molt de temps. Va ser el representant de l'Acadèmia al Congrés de Lingüística i Filologia Romàniques, celebrat a Mallorca el 1980, va fer articles al Butlletí sobre temes medievals i d'altres sobre autors contemporanis (Aribau, Salvador Espriu i Miquel Dolç). També són seus els discursos de contestació corresponents als ingressos de Joaquim Molas (1993) i Lola Badia (1996). Tanmateix, la més gran dedicació de Romeu dins de l'Acadèmia van ser les seves setze comunicacions en les sessions dels dijous. El 17 de febrer de 1994 es presentà a la seu de l'Acadèmia el volum de lírica Tots els poemes; el 20 de desembre de 2001, l'edició de Pere Serafí i el 30 de novembre de 2000, el poemari Ésser i estar (Diccionari biogràfic: 371).

Uns anys abans d'entrar Romeu a l'Acadèmia, essent Martí de Riquer vicerector de la Universitat Autònoma de Barcelona (ocupà aquest càrrec des del 1968 fins al 1976), va incorporar per formar part del nou professorat de la Facultat de Filosofia i Lletres (basant-se en la voluntat que el quadre docent fos un element realment distintiu i característic), gent valuosa que havia restat fora del món universitari (Gatell \& Soler 2008: 382-83). Així doncs, el 1969 el Dr. Josep Romeu i Figueras s'incorporà de forma definitiva a la Universitat Autònoma i va ser nomenat catedràtic de Filologia Catalana, on va impartir classes i seminaris de literatura catalana medieval fins a la seva jubilació, el 1984.

Quan Martí de Riquer es va jubilar, també l'any 1984, el seu entorn universitari més proper li va organitzar un seguit d'homenatges. El Symposium va ser una iniciativa del departament de Filologia Romànica de la Facultat de Filologia de la Universitat de Barcelona, impulsada per l'exalumne de Riquer i aleshores degà de la Facultat Gabriel Oliver, que va remoure totes les institucions universitàries per obtenir l'ajut econòmic necessari i es va desviure per tal de garantir que l'esdeveniment fos tot un èxit $V$ a convidar els romanistes europeus més prestigiosos - tots molt amics de Riquer - a pronunciar unes conferències tal com es feia als congressos de la Société Rencesvals, on l'intercanvi acadèmic es comple- mentava amb altres convocatòries de caire artístic i amical (Gatell \& Soler 2008: 531-40).1 A iniciativa de Lola Badia i Jaume Vallcorba es van anant publicant, en aquells mateixos anys, un conjunt molt nombrós d'estudis, els Studia in honorem prof. M. de Riquer. L'empresa va tenir una resposta massiva i van arribar molts articles que ocupen quatre volums molt gruixuts. ${ }^{12}$

Al primer volum apareix un article de Josep Romeu intitulat «Les dames cantades per Pere Serafí en els seus poemes catalans» (Studia 1986: 155-83).

El 8 de març de 1987 Riquer escriu a Romeu la carta següent:

Estimat amic. He llegit amb molta atenció i profit el bell treball que sobre les dames cantades per Pere Serafí has publicat al primer volum dels Studia a mi dedicats. És una completíssima contribució que fa plànyer que encara no hagis publicat la teva tan esperada edició de les poesies de «lo Grech».13 Però damunt de tot agraeixo de tot cor que m'hagis dedicat aquest estudi tan important, cosa que tant m'afalaga.

Amb la cordial abraçada de sempre del teu vell amic

Uns anys més tard, a l'Acadèmia de Bones Lletres i davant del seu amic Martí de Riquer, Josep Romeu presentava la seva edició crítica de les Poesies catalanes de Pere Serafí (Romeu i Figueras 2001).

També al Dr. Romeu li van fer un homenatge literari amb motiu de la seva jubilació de la Universitat Autònoma el 1984 que quedà reflectit en dos volums d'articles (Estudis 1986). Martí de Riquer i Lola Badia li van presentar l'edició i estudi dels poemes catalans de Ramon Boter, un poeta molt influenciat per Jordi de Sant Jordi i Ausiàs March (Riquer \& Badia 1986: 253-93). Romeu, un cop llegit l'article, va escriure a Riquer el 16 d'abril de 1986 una llarga carta d'agraïment, que és l'última de les seves conservades a l'Arxiu Riquer.

I, com sempre era habitual en ell, fa una minuciosa ressenya del treball fet pels dos filòlegs:

\footnotetext{
11. Les conferències van ser editades al Symposium in honorem prof. M. de Riquer, 1986, Barcelona: Quaderns Crema. 12. Studia in honorem prof. M. de Riquer, I, 1986; II, 1987; III, 1988; i ıv, 1991, Barcelona: Quaderns Crema.

13. El pintor i poeta Pere Serafí és anomenat «lo Grech» en una capitulació del 1536 per a pintar l'orgue de la catedral de Tarragona (Riquer \& Comas 1980: 594).
} 
Benvolgut amic,

Amb aquestes ratlles vull agrair-te molt sincerament la teva valuosa aportació als Estudis... que m'han estat oferts a iniciativa de I'AILLC, la UAB i les Publicacions de l'Abadia de Montserrat. Gràcies, doncs, per la teva companyia.

[... . L'estudi i l'edició que heu realitzat tu i Lola Badia són exhaustius i portats, no cal dir, amb mà de bons mestres en filologia. [...] Crec que el vostre és un treball meritori fet en el rigor i la competència de dos grans filòlegs, mestre tu i deixeble ella, que al seu torn va imposant-se.

Amb el sincer reconeixement, rep una forta abraçada del teu amic

[rúbrica]

Voldria acabar aquestes pàgines amb una anècdota que mostra la respectuosa amistat de més de cinquanta anys entre els dos filòlegs catalans.

[A les sessions de la Acadèmia de Bones Lletres]

Tret de la cadira més alta - reservada al president - no hi ha una cadira fixa per a cadascun dels membres, sinó una mena de costum que hom respecta. Martí de Riquer acostumava a seure sempre davant la porta, al costat de Josep Romeu per compartir el mateix cendrer. La mort de Romeu i la prohibició de fumar van posar fi a un dels seus costums més característics. (Gatell \& Soler 2008: 469). ${ }^{14}$

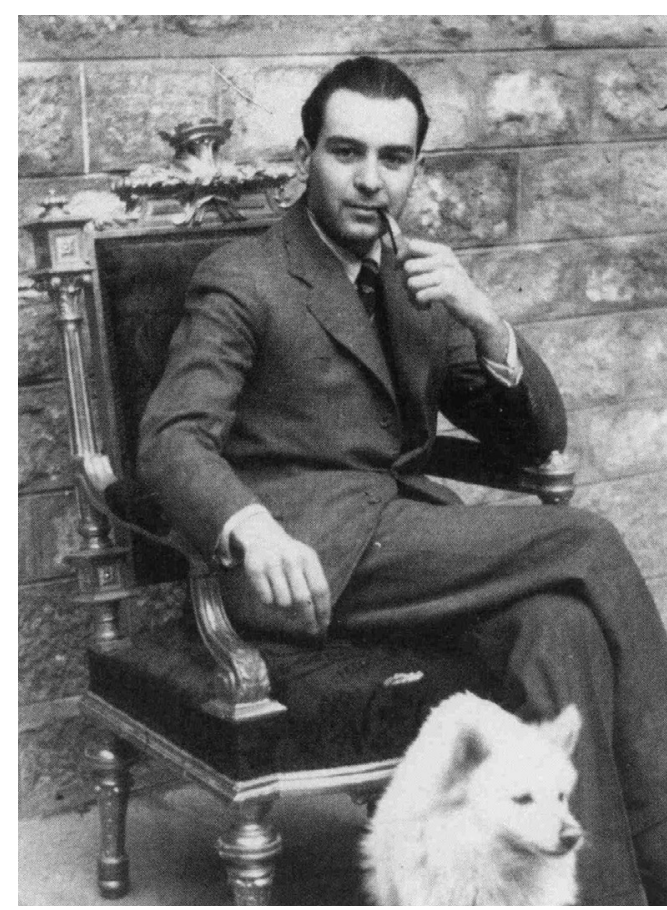

Martí de Riquer a l'Acadèmia el 1936. 


\section{Bibliografia citada}

Badia I Margarit, Antoni, 1989: Llavor de futur: 8 anys de rectorat, Barcelona: PAM.

BAdIA PÀmIES, Lola, 2012: Romeu i Figueras, Josep, Barcelona: Reial Acadèmia de Bones Lletres Fundació Noguera, 369-71.

Catàleg del Fons Romeu. Biblioteca Central d'lgualada. <htpp:// bibliotecavirtual.diba.cat/ documents/348184/476162/Romeu dossier_arxiu.pdf>

Diccionari biogràfic de l'Acadèmia de Bones Lletres, 2012: Barcelona: Reial Acadèmia de Bones Lletres Fundació Noguera.

Gatell, Cristina \& Glòria Soler, 2008 Martí de Riquer. Viure la literatura, Barcelona: La Magrana.
Riquer, Martí de \& Lola BADIA, 1986: «Les poesies de Ramon Boter i I'herència d'Ausiàs March», Estudis de literatura catalana en honor de Josep Romeu i Figueras, 2 vols., a cura de Lola Badia i Josep Massot i Muntaner, PAM, Universitat Autònoma de Barcelona, Associació Internacional de llengua i literatura catalanes, II, 253-93.

RiQuer Martí de \& Antoni ComAs, 1980: Història de la literatura catalana, 3 . Barcelona: Ariel.

Romeu I FIgueras, Josep, 1986: «Les dames cantades per Pere Serafí en els seus poemes catalans»), Studia in honorem prof. M. De Riquer, I, Barcelona: Quaderns Crema, 155-83.
Romeu I Figueras, Josep, 2001: Poesies catalanes. Pere Serafí, Barcelona: Barcino. Fundació Jaume I, «Els Nostres Clàssics, Collecció B 21»».

Studia in honorem prof. M. de Riquer I, 1986; II, 1987; III, 1988; i IV, 1991 Barcelona: Quaderns Crema.

Symposium in honorem prof. M. de Riquer, 1986: Barcelona: Quaderns Crema.

Vélez I Vicente, Pilar, 2012: Ainaud de Lasarte, Joan, Barcelona: Reial Acadèmia de Bones Lletres Fundació Noguera, 20-21.

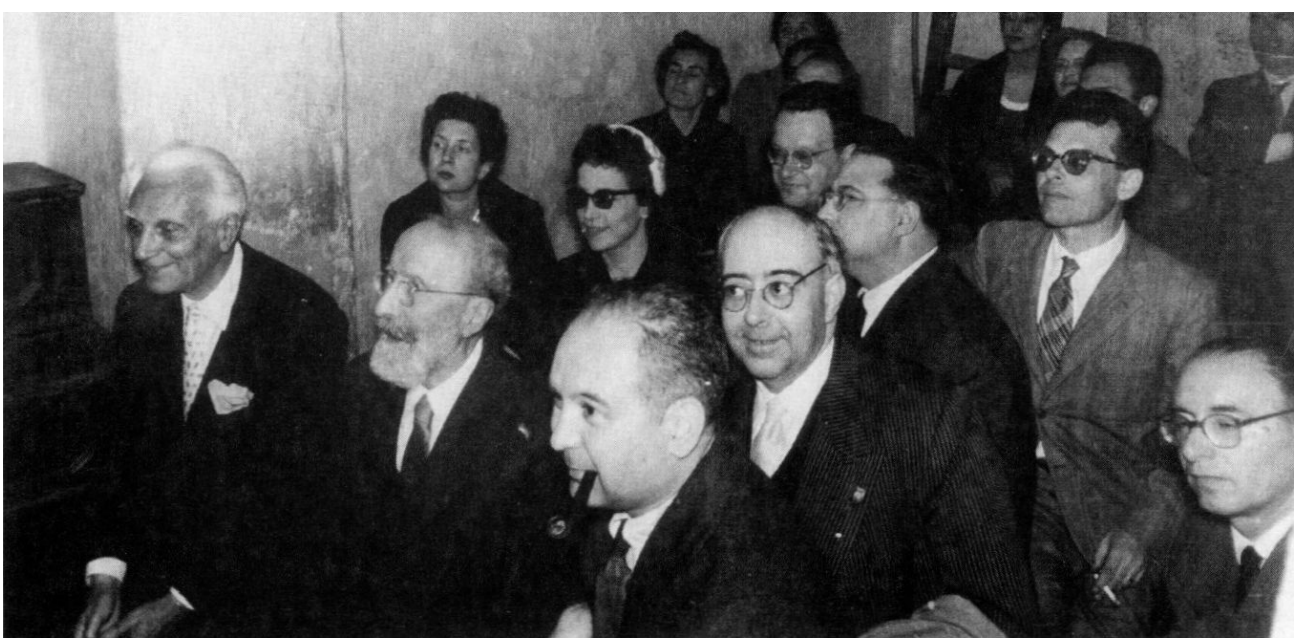

Palerm, 1955. Al Teatro dei Puppi, Martí de Riquer amb Angelo Monteverdi, Ramon Martí Permanyer, Ettore Li Gotti i Aurelio Roncaglia. 